\title{
Maksillofasiyal travma geçirmiş bir hastaya multidisipliner tedavi yaklaşımı: Olgu sunumu *
}

\author{
Önjen Tak ${ }^{1}$, Bahadır Kan², Zinde Güder ${ }^{1}$
}

Selcuk Dental Journal, 2015; 3: 144-149

Başvuru Tarihi: 06 Ağustos 2015 Yayına Kabul Tarihi: 01 Ekim 2015

\section{ABSTRACT \\ The multidisciplinary treatment approach of a patient with maxillofacial trauma: A case report}

Treatment of maxillofacial trauma patients is the most challenging cases and mostly these kinds of cases require multidisciplinary approach and individual treatment planning. The aim of this case report is to present the multidisciplinary treatment of a patient with the complaint of hard and soft tissue loss caused by maxillofacial trauma using implant supported fixed partial dentures.

A 47-year-old male patient was referred to our clinic with the complaint of tooth, bone and soft tissue loss caused by maxillofacial trauma. There was a fracture at the left mandibular region that was stabilized by surgical plates before. After healing, 5 dental implants for each jaw were placed. Metal frameworks that supported by custom abutments were fabricated and the definitive metalceramic and metal-composite resin restorations were inserted after verification of occlusion.

The patient's aesthetic and functional expectations were achieved immediately. At one-year follow-up no aesthetic, biological, functional and biomechanical complications were observed.

\section{KEY WORDS}

Dental implant, fixed partial dentures, maxillofacial injury, screw retained implant supported prosthesis
Maligniteler, dev kistler, enfeksiyonlar ve travmalara bağlı oluşan defektler maksilla ve mandibulada total ya da parsiyel dişsizliklere neden olabilmektedirler. Rehabilite edilmeyen defektler hastalarda estetik, fonksiyonel ve psikolojik zorlukları beraberinde getirmekte ve konvansiyonel protezler ile her zaman başarılı sonuçlar elde edilememektedir (Ericsson ve ark 1986, Sullivan 1986). Travma hastalarında kaybedilen yumuşak ve sert doku miktarına bağlı olarak implant destekli sabit protezler hastaların intiyaçlarını karşılayabilmektedir (McGlumphy ve Larsen 1998). Bununla birlikte ileri travma vakalarında standart tedavi planlamaları ile başarıya ulaşmak güç olabileceğinden vakaya özel yaratıcı çözümlerin üretilmesi gerekebilmektedir (Misch 1993).

Kişiye özel protetik planlamada; kayıp sert ve yumuşak dokular, kaybedilmiş ve ağızda varlığını sürdüren dişler, fibrotik skar dokusu, interark mesafe, okluzal düzlem, çeneler arası ilişki, gülme hattı gibi birçok faktör detaylı incelenerek hasta için en uygun tedavi planlaması oluşturulmalıdır (Misch 1993).

$\mathrm{Bu}$ olgu sunumunda; çalıştığı iş yerinde basınçlı bir mekanik cihazın patlayarak, maksilla ve mandibulasında çeşitli sert-yumuşak doku ve diş kayıpları ile kırıklara yol açan bir iş kazası sonucu estetik ve fonksiyonel beklentiler içerisinde olan bir hastanın vida ve siman tutuculu implant üstü sabit protezler ile rehabilitasyonu anlatımaktadır.

\footnotetext{
* Bu olgu sunumunun 6 aylık takibi 2014 yılında İstanbul'da düzenlenen 38. EPA Yıllık Kongresi-21. TPID Bilimsel Kongresi’nde sunulmuştur.

${ }^{1}$ Kocaeli Üniversitesi Diş Hekimliği Fakültesi Protetik Diş Tedavisi Anabilim Dalı, Kocaeli

${ }^{2}$ Kocaeli Üniversitesi Diş Hekimliği Fakültesi Ağız, Diş ve Çene Cerrahisi Anabilim Dalı, Kocaeli
} 


\section{OLGU SUNUMU}

Kocaeli Üniversitesi Diş Hekimliği Fakültesi Protetik Diş Tedavisi Anabilim Dalı Kliniği'ne yönlendirilen 47 yaşında erkek hasta, çalıştığı basınçlı bir cihazın patlaması sonucu maksillofasiyal bir travma geçirmiş, yumuşak dokudaki yaralanmaların dışında mandibulanın sol bölgesinde bir kırık oluşmuştur. Travma sonucu 11, 12, 14, 15, 16, 21, $22,31,32,33,34,36,41$ ve 42 numaralı dişler kaybedilmiş, 35, 43, 44, 45 numaralı dişler çeşitli seviyelerden kırılmış ve 13 numaralı diş intrüze olmuştur. Hastanın ilk müdahalesi iş yerinde yapıldıktan sonra hospitalize edilmiş, mandibular fraktür bölgesi mini plaklarla fikse edilmiş ve plastik cerrahi operasyonları ile yumuşak doku rekonstrüksiyonları yapıldıktan ve iyileşmeleri tamamlandıktan sonra kliniğimize protetik tedavisinin yapılması amacıyla yönlendirilmiştir (Resim 1).

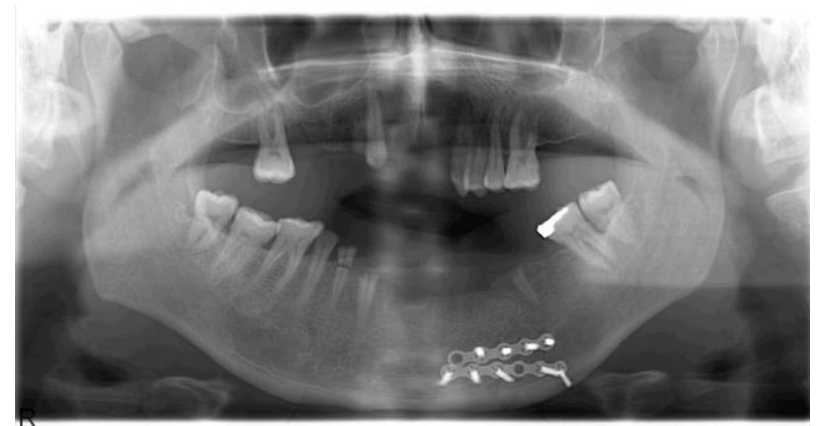

Resim 1.

Başlangıç panoramik radyografisi

Herhangi bir sistemik rahatsızlığı bulunmayan hastanın estetik ve fonksiyonel beklentileri değerlendirildi. Yapılan klinik ve radyografik muayene sonucunda hasta; tedavi seçenekleri, risk, yarar ve maliyetler konusunda bilgilendirildi ve aydınlatılmış onamı alınarak implant destekli sabit protez yapımına karar verildi. Öncelikle prognozu şüpheli olan $13,17,35,43,44$ ve 45 numaralı dişler çekildi. 26 numaralı dişte var olan perküsyon hassasiyeti nedeniyle endodontik tedavi yapıldı ve hasta ağız bakımı konusunda motive edildi (Resim 2). Klinik muayenede alt dudakta bulunan skar dokusunun, konuşma ve gülümseme sırasında alt dudağın sağ tarafının daha yukarıda pozisyonlanmasına sebep olduğu, ayrıca hastada yüksek gülme hattı varlığı belirlendi.

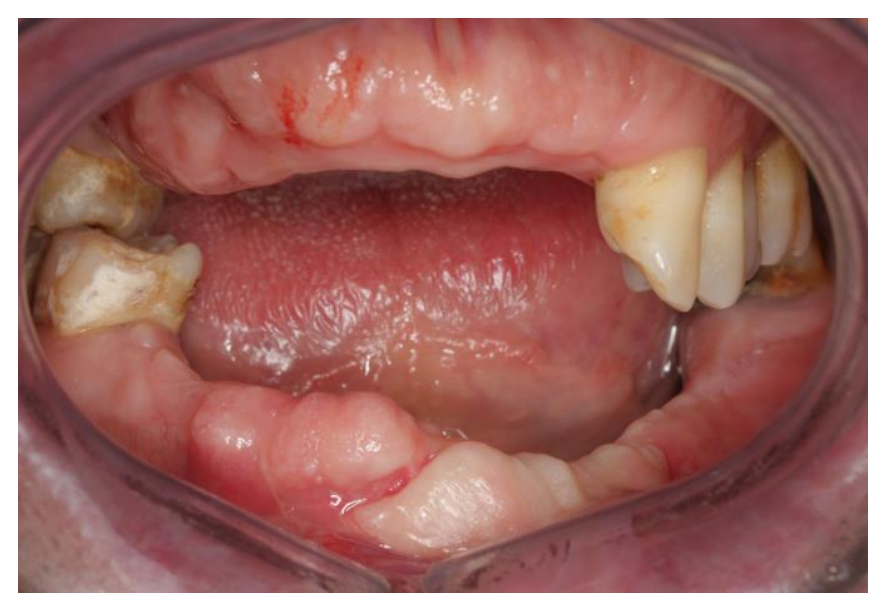

Resim 2.

İmplant yerleşimi öncesi ağız içi görünüm

Aljinat ölçü maddesi (CA37, Cavex, Hollanda) kullanılarak alınan ölçülerden elde edilen teşhis modelleri artikülatörde incelendi. Tedavi sonunda elde edilmesi beklenilen estetik sonuçların değerlendirilmesi için mock-up provaları yapıldı (Resim 3) ve hastaya her iki çenede beşer adet implant destekli sabit parsiyel protez ile okluzal mesafenin yeterli olmaması sebebiyle 46 numaralı dişe veneer kron restorasyonu yapılması planlandı. Teşhis modelleri üzerinde üretilen teşhis protezleri ve konik ışınlı bilgisayarlı tomografi yardımı ile (Resim 4) mandibular fraktür bölgesindeki mini plak vidaları ile çakışmayacak konumda implantlar planlandı. Teşhis protezinde ilgili dişlerin okluzal tablalarında rehber oluklar hazırlanarak geleneksel cerrahi kılavuz oluşturuldu.

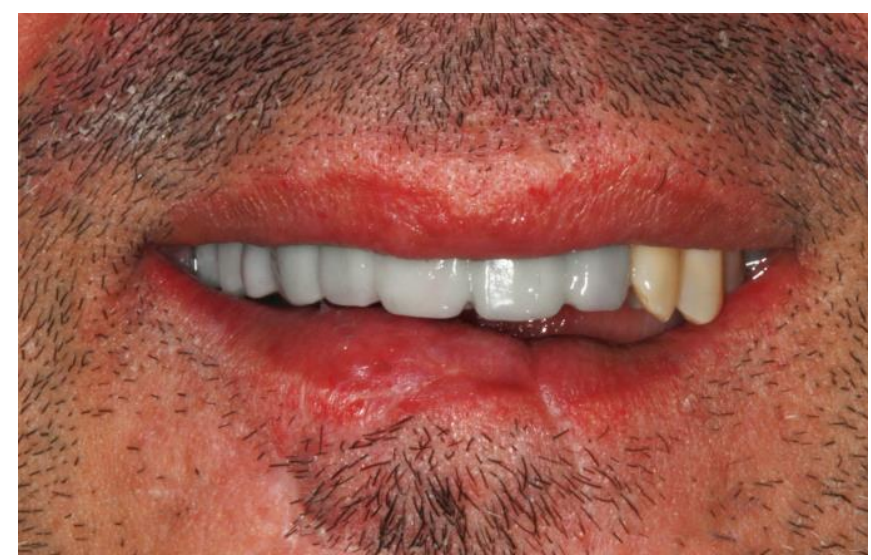

Resim 3.

Mock-up provası 


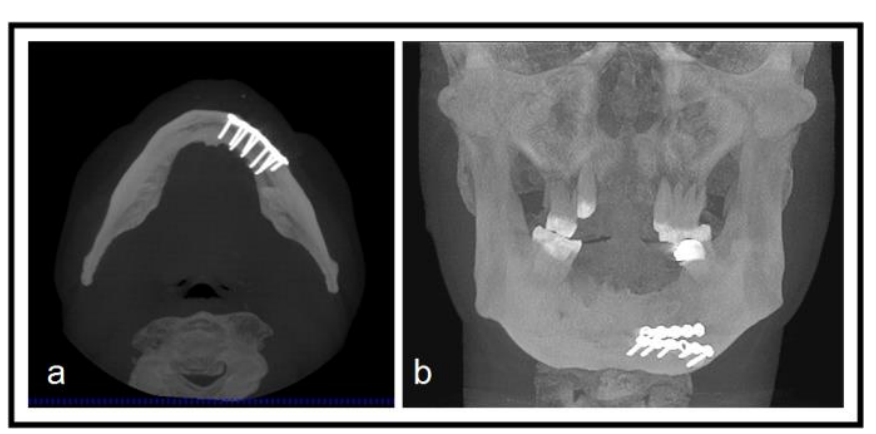

Resim 4.

Konik ışınlı bilgisayarlı tomografi multi planner rekonstrüktif görüntü
a) aksiyel kesit
b) koronal kesit

Oluşturulan geleneksel cerrahi kılavuz yardımı ile lokal anestezi altında, maksillada 13, 15, 16, 17 ve 22 numaralı bölgeler ile mandibulada $35,36,41,43$ ve 45 numaralı bölgelere beşer adet kemik seviyesi implant (Astra tech, Dentsply, İsveç) yerleştirildi (Resim 5). Osseointegrasyon süreci sonrasında ikinci cerrahi ile iyileşme başlıkları yerleştirildi. Bir haftalık iyileşme periyodunun ardından, teşhis modelleri üzerinde akrilik rezin ile (Light curing trayplates, Vertex Dental, Hollanda) kişisel ölçü kaşıkları hazırlandı ve implantların açık kaşık ölçü postları implantlara yerleştirildi. Ölçü içerisinde olası bir yer değiştirmeye engel olmak amacıyla paslanmaz çelik tel ve akışkan kompozit rezin (Clearfil Majesty Flow, Kuraray, Japonya) kullanılarak ölçü postları birbirlerine fikse edildi. Her iki çenenin ölçüsü polieter ölçü maddesi (Impregum, 3M ESPE, Almanya) kullanılarak açık kaşık ölçü yöntemiyle elde edildi. Elde edilen ana modeller üzerinde kaide ve mum duvarlar hazırlanarak hastanın çeneler arası ilişkisi kaydedildi.

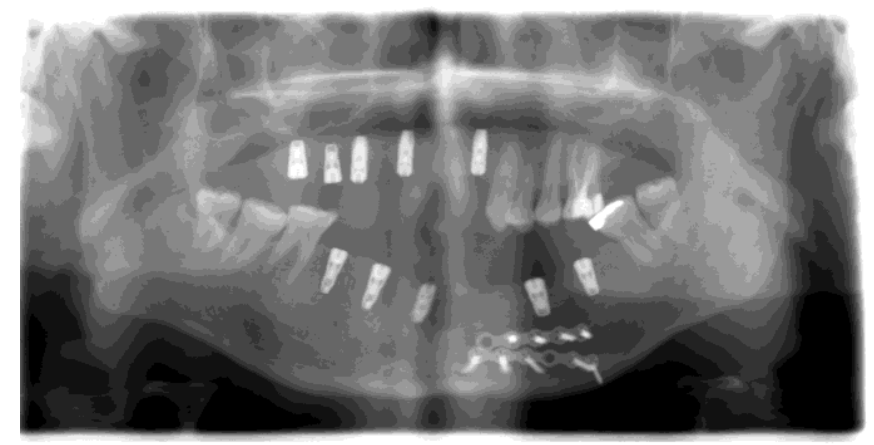

Resim 5.

İmplant yerleşimi sonrası panoramik radyografi

Laboratuvara gönderilen ana modeller üzerinde, okluzal vidalarla implantlara sabitlenen, kişisel abutmentlar ile entegre olan tek parça metal altyapılar üretildi (Resim 6, Resim 7, Resim 8) ve metal altyapıların pasif uyumu klinik ve radyografik olarak kontrol edildi. Maksiller anterior bölgede vida çıkış deliklerinin labioinsizalde konumlanması sebebiyle 11,
12, 13, 21 ve 22 numaralı bölgelerdeki restorasyonlar metal alt yapı üzerine simante edilecek seramik veneer kronlar şeklinde üretildi. Anterior bölgede metal altyapının servikal bölgesinde pembe porselen kullanılarak ideal kron oranları elde edilmeye çalışıldı. Maksiller posterior bölgede ise seramik materyal metal altyapı üzerine direkt olarak işlendi. Mandibulada ideal okluzal kuvvet dağılımını sağlamak ve karşılıklı restorasyonlarda oluşabilecek stresi azaltarak olası komplikasyonları önlemek amacıyla metal altyapı üzerine kompozit rezin estetik materyal (Gradia Indirect, GC Chemicals, Japonya) işlendi.

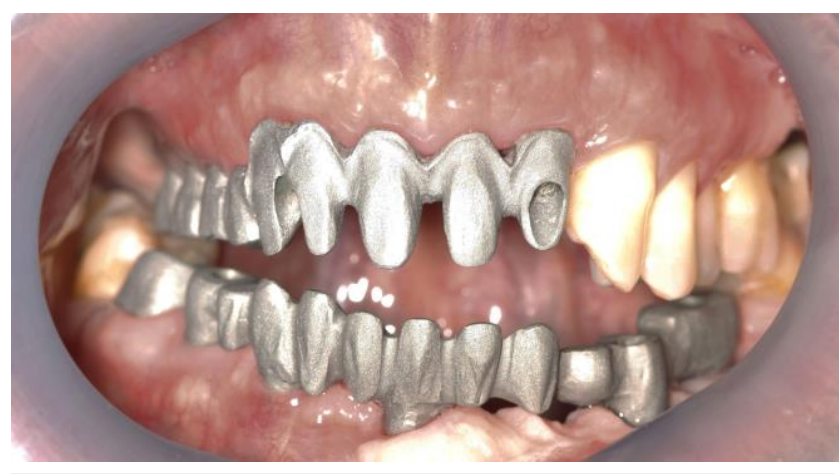

Resim 6.

Metal altyapı provası (frontal görüntü)

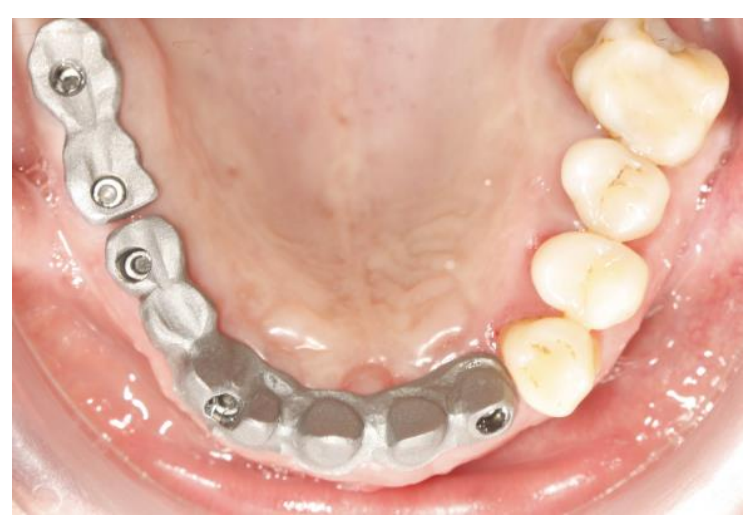

Resim 7.

Metal altyapı provası (üst çene okluzal görüntü)

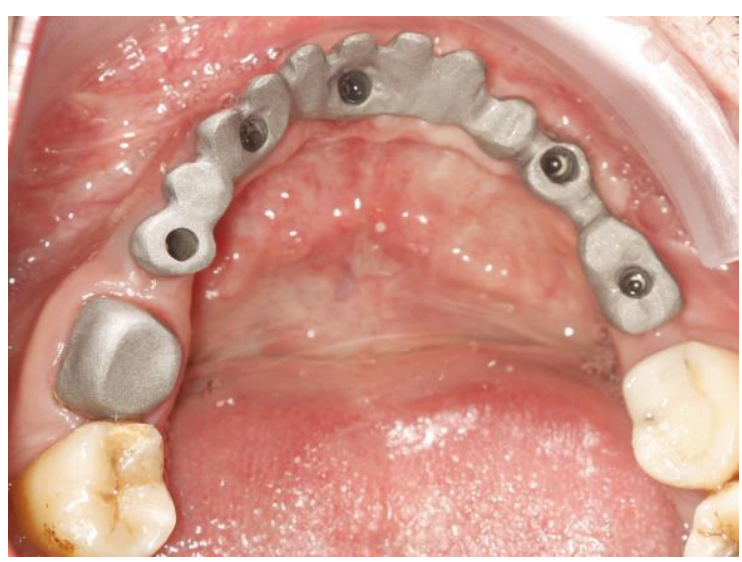

Resim 8.

Metal altyapı provası (alt çene okluzal görüntü) 
Restorasyonlar ağız içerisinde marjinal uyum, internal adaptasyon, okluzal kontaktlar, okluzyon ve artikülasyon açısından değerlendirilerek gerekli uyumlamalar yapıldı. Maksiller metal-seramik restorasyonlarda glazürleme işlemi, mandibular metal-kompozit rezin restorasyonlarda ise cila diskleri ile polisaj işlemleri yapılarak restorasyonlar bitirildi. Kişisel abutmentlara entegre üretilen tek parça metal altyapılar tork aleti (Astra tech, Dentsply, Isveç) kullanılarak $35 \mathrm{Ncm}$ tork ile sabitlendi. Maksiller anterior bölgedeki ve 46 numaralı diş üzerindeki veneer kronlar çinko polikarboksilat siman (Adhesor Carbofine, Spofa Dental, Almanya) kullanılarak simante edildi (Resim 9, Resim 10). Hasta protezin bakımı ile ilgili bilgilendirildi ve ağız sağlığı konusunda motive edildi. Hastanın tedavi sonrası 1, 3, 6 ve 12. ayda periyodik kontrolleri yapıldı, kısa dönemde klinik ve radyolojik olarak herhangi bir soruna rastlanmadı (Resim 11, Resim 12, Resim 13).

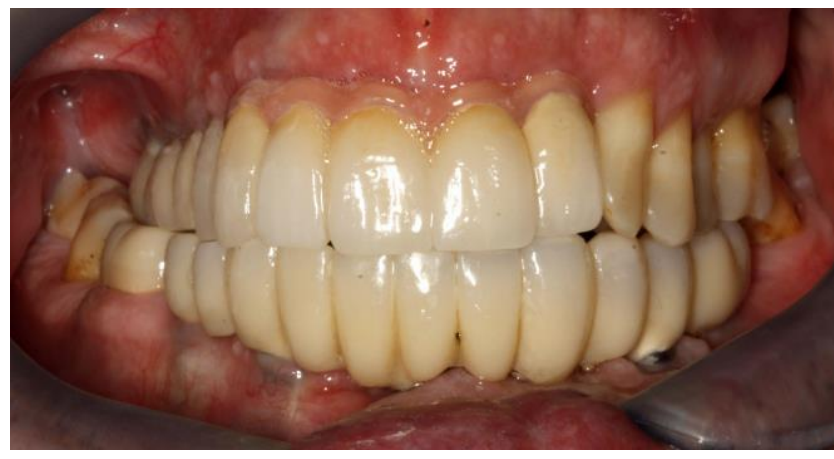

Resim 9.

Restorasyonların ağız içi görünümü

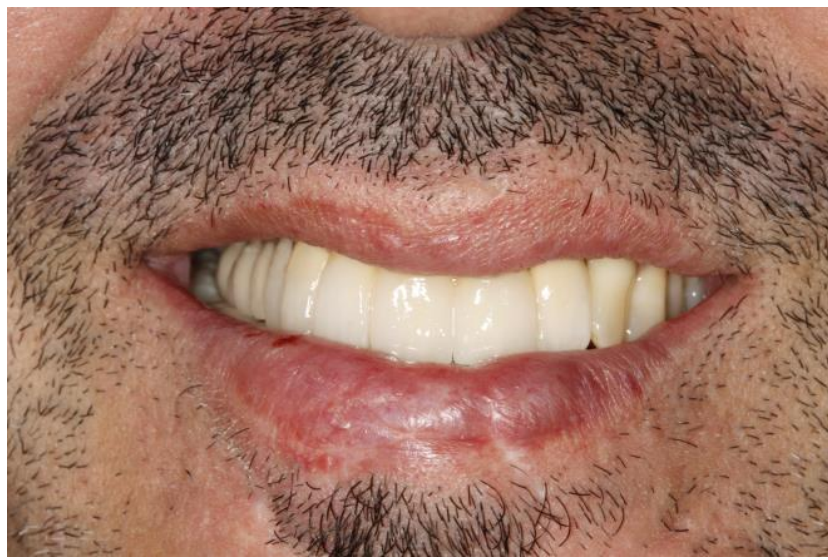

Resim 10.

Final görünüm (gülümseme)

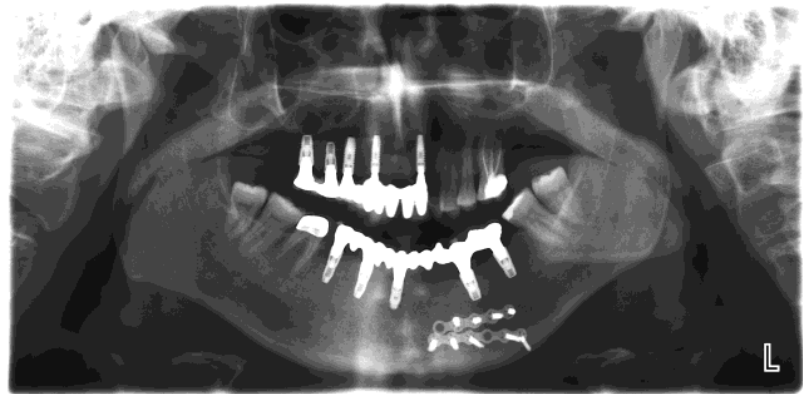

Resim 11.

Bir yıllık takip - panaromik radyografi

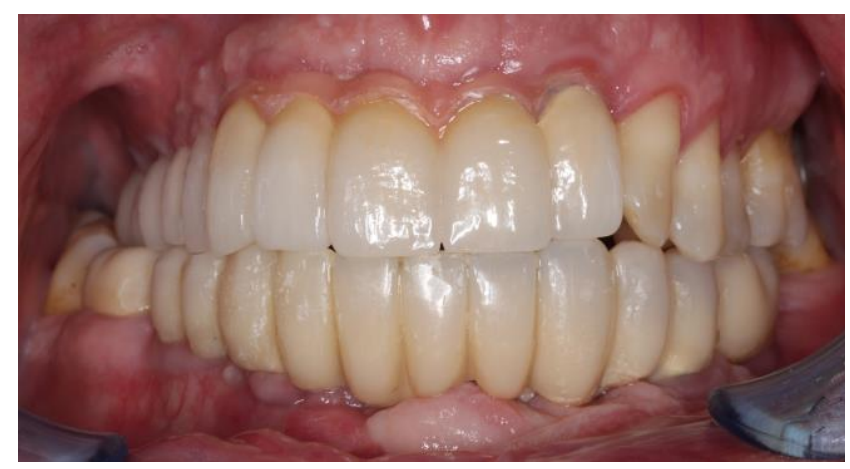

Resim 12.

Bir yıllık takip - ağız içi görünüm

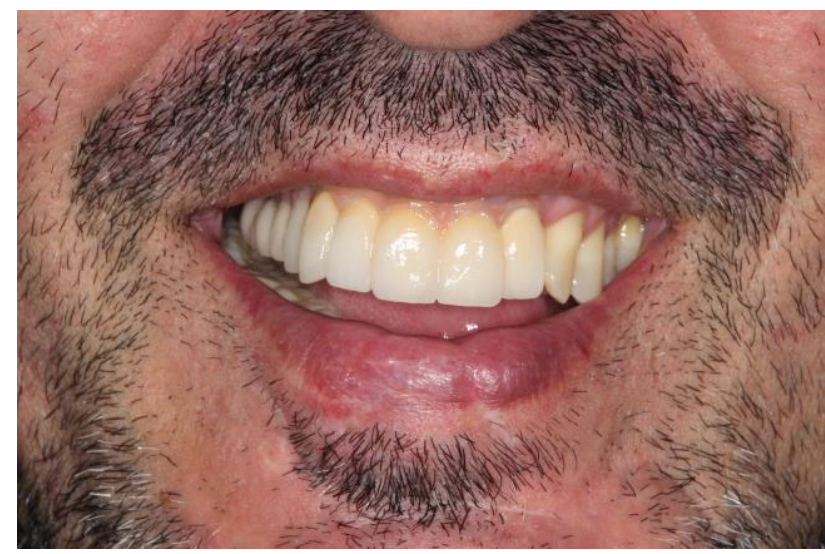

Resim 13.

Bir yıllık takip - gülümseme 


\section{TARTIŞMA}

Maksillofasiyal travma hastalarında tatmin edici bir sonuç elde etmek için özenli bir çalışma ve multidisipliner yaklaşım büyük önem arz etmektedir. Bu vakada kırık dişlerin ağızda tutulması ve protetik planlamaya dahil edilmesi, estetik sonuçlarla birlikte uzun dönem prognozu da riske atabileceğinden (Ploumaki ve ark 2013) prognozu şüpheli dişlerin çekilmesine ve bu bölgelerin de implant destekli sabit protez planlamasına dahil edilmesine hastanın onamı alınarak karar verildi. Kayıp dişlerin sayısı ve pozisyonlarının dışında planlama ve sonuca direkt etki eden bir diğer faktör ise kaybedilen alveol kemiği ve yumuşak doku konfigürasyonudur. Yumuşak doku cerrahilerinden sonra oluşan esnekliği azalmış skar dokusu, final restorasyonda estetik görünümü doğrudan etkileyecek önemli faktörlerden biridir.

Bu vakada özellikle kırık hattının olduğu sol mandibular bölgede, diğer bölgeler ile vertikal kemik yüksekliği farkı bulunmaktaydı. Yetersiz vertikal boyutlardaki kemiklerin yükseltilmesi farklı tekniklerle yapılmaya çalışılmaktadır. Onley otojen kemik ogmentasyonları sık kullanılan tekniklerden biridir (Chiapasco ve ark 2007, Verdugo ve ark 2012). Fakat uzun dönem sonuçlar onley kemik ogmentasyonlarının ciddi şekilde rezorpsiyona uğrayarak başarısızlıklara yol açtığını göstermiştir (Roccuzzo ve ark 2007). Diğer bir vertikal kemik kazanma tekniği ise alveoler distraksiyon osteogenezisidir (Kim ve ark 2013, Mampilly ve ark 2014). Fakat bu teknik kullanılarak kazanılmış kemik üzerine uygulanan implantların uzun dönem başarıları hakkında literatürde pek fazla bilgi mevcut değildir (Block ve ark 2000). Ayrıca ilgili bölgede skar dokusu varlığı distraktör kullanımını zorlaştırabilmektedir. Kullanılan ekipmanın maliyeti de hasta açısından düşündürücüdür. Hastanın ikinci bir cerrahi işlem istememesi ve ogmentasyon işlemlerinin başarısız olabilme riski nedeniyle vertikal ogmentasyon yapılması tercih edilmemiş, maksiller ve mandibular anterior bölgedeki kemik kaybının protetik olarak giderilmesine karar verilmiştir. Fakat bu karar, kullanılacak olan protetik altyapının tasarımını etkilemiştir. Elde edilecek restorasyonun kron/implant oranı artacağından, standart protetik parçaların özellikle maksiller ve mandibular anterior bölgede yapılacak olan restorasyonu desteklemekte yetersiz kalacağı düşünülerek kişisel abutmentlarla entegre bir metal altyapı ile restorasyonun desteklenerek direncinin arttırılması hedeflenmiştir.
Maksillada metal destekli seramik, mandibulada ise metal destekli indirekt kompozit rezin restorasyonları tercih edilmiştir. Bu sayede seramik üst yapı ile kapanışta bulunan kompozit rezin materyalinin daha düşük olan Young modülüsü sayesinde daha başarılı okluzal stres dağılımı sağlayarak, üstyapı ve implantlara iletilen kuvvetlerin azaltılması amaçlanmıştır (Juodzbalys ve ark 2005).

$\mathrm{Bu}$ vakada hastanın beklentisi sabit bir protez yapılması yönünde olduğundan tedavi alternatifi olarak implant destekli bir hareketli protez tercih edilmemiştir. Tedavi sonrasında hastanın estetik ve fonksiyonel beklentileri başarılı bir şekilde karşılanmıştır. Hasta restorasyonun bitirilmesini takiben özellikle alt dudaktaki skar dokusunun fonksiyon sırasında dudağı daha yukarıda pozisyonlandırması sebebiyle dudak ısırma problemiyle karşılaşmıştır. Fakat bu problem ilk 2 haftalık periyottan sonra azalarak kaybolmuştur. Hastanın 12 aylık takibi sonucunda herhangi bir estetik, biyolojik, fonksiyonel ya da biyomekanik komplikasyonla karşılaşılmamıştır.

Maksillofasiyal travma hikayesi olan hastalarda hareketli protezlere kıyasla daha iyi çiğneme fonksiyonu, estetik ve yüksek hasta memnuniyeti sağlayan implant destekli sabit restorasyonları kapsayan multidisipliner tedaviler ile memnun edici başarılı sonuçlar elde edilebilir ve tedavi planlamasında öncelikli olarak tavsiye edilebilir. 


\section{ÖZET}

Maksillofasiyal travma geçirmiş bir hastaya multidisipliner tedavi yaklaşımı: Olgu sunumu

Maksillofasiyal travma geçirmiş hastaların tedavisi başarı sağlamakta en çok zorlanılan vakaların başında gelmekte ve genellikle multidisipliner yaklaşım ile vakaya özel bir planlama gerektirmektedir. $\mathrm{Bu}$ olgu sunumunun amacı geçirdiği maksillofasiyal travma nedeniyle sert ve yumuşak doku kaybı şikayeti olan bir hastanın implant destekli sabit parsiyel protezler ile gerçekleştirilen multidisipliner tedavisini sunmaktır.

47 yaşında erkek hasta geçirdiği maksillofasiyal travma nedeniyle diş, kemik ve yumuşak doku kaybı şikayeti ile kliniğimize başvurdu. Mandibular sol bölgede daha önce cerrahi plaklarla stabilize edilmiş bir fraktür gözlendi. İyileşme sonrasında her bir çeneye beşer adet dental implant yerleştirildi. Kişisel abutmentlar ile entegre olan tek parça metal altyapılar üretildi ve okluzyon kontrolü sonrasında metal-seramik ve metalkompozit rezin restorasyonlar hastaya teslim edildi.

Hastanın estetik ve fonksiyonel beklentileri tedavi sonrasında başarılı bir şekilde karşılandı. 1 yıllık takip sonucunda herhangi bir estetik, biyolojik, fonksiyonel ya da biyomekanik komplikasyon gözlenmedi.

\section{ANAHTAR KELIMELER}

Dental implant, maksillofasiyal yaralanma, sabit parsiyel restorasyon, implantüstü sabit protez

\section{KAYNAKLAR}

Block MS1, Gardiner D, Almerico B, Neal C, 2000. Loaded hydroxylapatite-coated implants and uncoated titanium-threaded implants in distracted dog alveolar ridges. Oral Surg Oral Med Oral Pathol Oral Radiol Endod, 89, 676-685.

Chiapasco M, Zaniboni M, Rimondini L, 2007. Autogenous onlay bone grafts vs. alveolar distraction osteogenesis for the correction of vertically deficient edentulous ridges: a 2-4-year prospective study on humans. Clin. Oral Implant Res, 18, 432-440.
Ericsson I, Lekholm U, Brånemark PI, Lindhe J, Glantz PO, Nyman S, 1986. A clinical evaluation of fixed bridge restoration supported by the combination of teeth and osseointegrated titanium implants. J Clin Periodontol, 13, 307-312.

Juodzbalys G, Kubilius R, Eidukynas V, Raustia AM, 2005. Stress distribution in bone: single-unit Implant prostheses veneered with porcelain or a new composite material. Implant Dent, 14, 166-175.

Kim JW, Cho MH, Kim SJ, Kim MR, 2013. Alveolar distraction osteogenesis versus autogenous onlay bone graft for vertical augmentation of severely atrophied alveolar ridges after 12 years of long-term follow-up. Oral Surg Oral Med Oral Pathol Oral Radiol, 116; 540-549.

Mampilly MO, Rao LP, Sequiera J, Rao BH, Chandra J, Rai G, 2014. Rehabilitation of edentulous atrophic anterior mandible - the role of vertical alveolar distraction osteogenesis. J Clin Diagn Res, 8, ZR01-3.

Mcglumphy EA, Larsen PE, 1998. Contemporary oral and maxillofacial surgery. In: Contemporary implant dentistry, Ed; Peterson LJ, Ellis E, Hupp JR, Tucker MR, Third Edition, Mosby, St Louis, USA, pp; 369-405.

Misch CE, 1993. Contemporary implant dentistry. Second Edition, Mosby-Year Book Inc, St Louis, USA, pp; 20, 10321, 123-55, 187, 241-55.

Ploumaki A, Bilkhair A, Tuna T, Stampf S, Strub JR, 2013. Success rates of prosthetic restorations on endodontically treated teeth; a systematic review after 6 years. J Oral Rehabil, 40, 618-630.

Roccuzzo M, Ramieri G, Bunino M, Berrone S, 2007. Autogenous bone graft alone or associated with titanium mesh for vertical alveolar ridge augmentation: A controlled clinical trial. Clin Oral Implant Res, 18, 286-294.

Sullivan DY, 1986 Prosthetic considerations for the utilization of osseointegrated fixtures in the partially edentulous arch. Int J Oral Maxillofac Implants, 1, 39-45.

Verdugo F, D'Addona A, Pontón J, 2012. Clinical, tomographic, and histological assessment of periosteal guided bone regeneration with cortical perforations in advanced human critical size defects. Clin Implant Dent Relat Res, 14, 112-120.

\section{Yazışma Adresi}

Yrd.Doç.Dr.Önjen TAK

Kocaeli Üniversitesi Yuvacık Yerleşkesi

Diş Hekimliği Fakültesi

Protetik Diş Tedavisi AD

41190 Yuvacık, Başiskele, Kocaeli

Tel: 0 (262) 3442111

Faks: 0 (262) 3442109

E-mail: onjentak@hotmail.com 